\title{
Paisagem e Cultura: Agache e a Entrada do Brasil
}

\section{Lucia M. Costa}

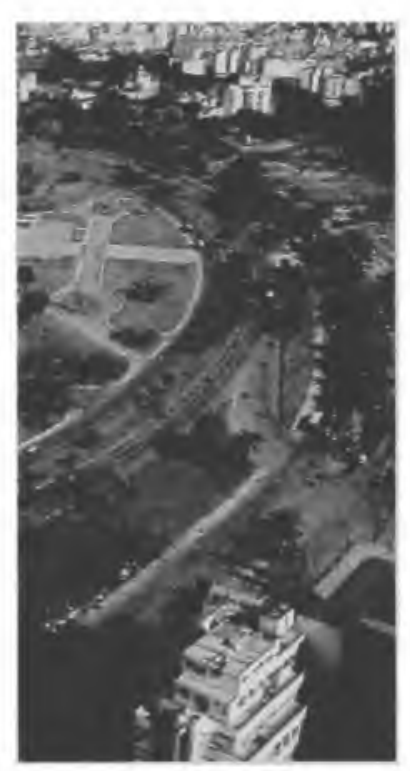

Arquiteta, Ph.D. pela University College London, professora titular de Paisagismo,

PROURB / FAU - UFRJ

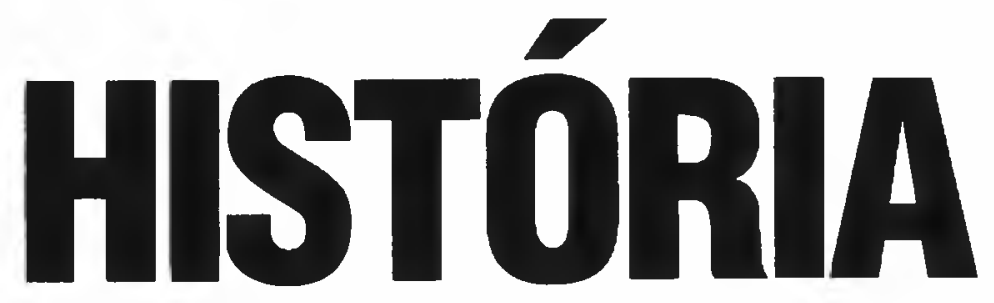




\title{
Paisagem e Cultura: Agache e a Entrada do Brasil
}

\begin{abstract}
A Baía de Guanabara, lugar privilegiado em termos de beleza, história e situação geográfica, tem um forte significado simbólico para os habitantes do Rio de Janeiro. Sua paisagem, na verdade, confunde-se com a imagem da cidade. Neste sentido, desde o século 19 sucederam-se diversas propostas de expansão e uso nessa área da cidade pelo aterro na baía.
\end{abstract}

Este trabalho discute uma destas idéias: a praça monumental proposta pelo urbanista francês Alfred Agache em 1930, situada às margens da Baía de Guanabara, onde hoje é a Marina da Glória, no Parque do Flamengo. Esta praça, que ele denominou a "Entrada do Brasil" é extremamente reveladora dos valores que nortearam a proposta de Agache para a cidade como um todo, e traz em seu desenho um conteúdo ideológico que transcende sua aparência físico-espacial.

O Plano Agache - como ficou conhecido - traz propostas relativas a zoneamento, legislação, desenho urbano, tráfego, entre outras. Apresenta, inclusive, pela primeira vez na história da cidade, um plano global e sistemático de tratamento das áreas livres públicas, que são tratadas no seu conjunto e não isoladamente como vinha acontecendo até então' Este trabalho se atém, no entanto, apenas à discussão da proposta de criação de uma praça cívica às margens da Baía de Guanabara, apresentando inicialmente o Plano Agache em termos gerais e depois se dirigindo especificamente ao projeto da Entrada do Brasil. O trabalho argumenta que a paisagem construída da "Entrada do Brasil" não incorpora elementos da paisagem natural circundante em seu projeto e busca trazer, em contrapartida, novos valores estéticos, culturais e de "civilidade" para a cidade do Rio de Janeiro.

(1) Para um estudo detalhado do sistema de áreas livres públicas proposto por Agache para o Rio de Janeiro, ver Costa, L. M. S. A. 1993. Popular values for urban parks: A case study of the changing meanings of Parque do Flamengo in Rio de Janeiro. Ph.D. Thesis, University College London. 


\title{
- plano Agache
}

Alfred Agache, arquiteto urbanista francês, desenvolveu, entre 1927 e 1930, o primeiro plano diretor para o Rio de Janeiro, por solicitação do prefeito Prado Júnior. O Rio de Janeiro estava passando por um intenso crescimento populacional devido à migração das áreas rurais e, como conseqüência, a população quase dobrou em tamanho entre 1920 e 1930 (Resende, 1982). A cidade estava crescendo rapidamente e de um modo desorganizado, causando problemas que estavam além do controle do poder público. Resende (1982) argumenta que o Plano Agache surgiu da necessidade de submeter o espaço urbano às exigências do setor industrial emergente, "demandando infra-estrutura viária e de saneamento, bem como o embelezamento e remodelação em função dos valores estéticos desta mesma burguesia urbana" (p. 39). A tarefa de Agache seria a de criar um plano urbanístico capaz de transformar completamente a capital do Brasil em termos funcionais, estéticos e socioeconômicos. Como bem destaca Underwood:

\begin{abstract}
"Apesar da indiscutivel beleza de sua paisagem natural, o Rio tinha um sério problema de imagem. Aos olhos das elites brasileiras, faltava ainda à cidade os atributos arquitetônicos e urbanísticos de uma capital internacional. " (1991, p. 131-1321
\end{abstract}

A escolha de um arquiteto francês para criar uma nova imagem para o Rio foi ao encontro dos valores culturais e estéticos de uma elite carioca que já vinha há muito tempo olhando para Paris como modelo de cultura, comportamento e modernização. Por outro lado, também representava uma oportunidade ideal para a elite cultural francesa disseminar suas idéias. Alfred Agache possuía o título de "Arquiteto do Governo Francês" e foi um dos fundadores da Societé Française de Urbanism no início dos anos 20 (Evenson, 1973, Bruant, 1996). Ele se empenhou muito em disseminar a escola de urbanismo francesa no exterior (Underwood, 19911 .

No seu plano, Agache expressou sua admiração pelo trabalho de Daniel Burnham, Patrick Gueddes e Ebenezer Howard (Agache, 1930, p. 25). Evenson (1973) aponta algumas semelhanças entre a proposta de Agache para o Rio de Janeiro e a proposta de Burnham para Chicago em 1908, particularmente na ênfase em alcançar uma monumentalidade pelos conjuntos arquitetônicos e urbanísticos de caráter cívico, em que o desenho baseia-se nos princípios da Écòle de Beux Arts.

Na introdução do plano, Agache explica suas idéias sobre urbanismo e porque ele era necessário para a cidade:

A cidade do Rio de Janeiro, com sua inegualável moldura, a sua cabeleira de florestas, o seu colar de pérolas elétricas, o espelho dágua no qual se mira, está, contudo, sob a ação de um certo enfraquecimento (...)" (Agache, 1930, 5) 
Nesse discurso inicial, repleto de metáforas curiosas, Agache vai além de simplesmente tecer uma analogia entre a cidade e o corpo humano: o Rio de Janeiro era uma mulher. Uma mulher linda e vaidosa que, entretanto, estava doente. Agache se apresenta como o "médico" capaz de curar tal formosa mulher pelo "diagnóstico" das causas da doença e da "prescrição" do receituário que certamente irá curá-la: um tratamento urbanístico!

A metáfora do organismo humano permeia o discurso usado por Agache para apresentar a sua proposta para a cidade. Por meio do plano, as funções da cidade são comparadas com as funções do corpo humano. Na cidade, o sistema circulatório é formado pelas ruas e avenidas; o sistema digestivo é representado pelos sistemas de água e esgoto; o sistema nervoso é composto pelos serviços de correios, telégrafos e telefone; e o sistema respiratório é formado pelos espaços verdes e áreas livres.

Agache "diagnosticou" o principal problema do Rio de Janeiro como sendo uma falta de controle sobre a expansão da cidade e o rápido crescimento populacional. O controle seria conseguido pela implementação de um número de objetivos, como descritos no plano: zoneamento da cidade de acordo com elementos funcionais; uma política habitacional "para diferentes categorias de habitantes" (Agache, 1930, p. 20); reestruturação do sistema de tráfego e a implementação de legislação urbana (p.120). Agache desenvolve então uma série de propostas para diferentes áreas da cidade, enfatizando estética e funcionalidade conforme a situação |ver Resende, 1985, 1999).

\section{A Entrada no Brasil}

Agache dedicou especial atenção à área central do Rio de Janeiro - o coração cultural, político e administrativo da cidade e do país. Para trazer ao Rio uma nova imagem, que fosse ao encontro dos padrões de desenho urbano europeus e às expectativas das elites brasileiras da época, Agache se sentiu à vontade para modificar a topografia da cidade a fim de adaptá-la a seus propósitos. Ao mesmo tempo em que exaltava a paisagem natural do Rio em seu plano, Agache, diplomaticamente reforçava a necessidade de alterá-la a fim de acomodar as reformas urbanas que ele considerava importantes:

"A situação geográfica do sítio tem um valor tal, comporta tantos privilégios $e$ promessas de futuro, que sua excellência permitiu e permitirá ainda durante muito tempo ao homem, de corrigir por meio de grandes obras o que pode haver de desfavorável ou incômmodo na sua configuração topográfica. A cidade do Rio de Janeiro goza da grande vantagem de poder, de um certo modo, forçar a natureza convencida de que o esfôrço será compensado; desta vantagem ela se aproveita e deverá aproveitar-se ainda por muito tempo " (Agache, 1930, p.159 - grifo originall. 
Em outras palavras, a "excelência" da paisagem do Rio situava-se também na sua maleabilidade em se adaptar a novos valores. $E$, se a topografia da cidade podia tão facilmente adaptar-se a novos valores estrangeiros, no que diz respeito a novos padrōes de espaço urbano, provavelmente poderia esperar-se o mesmo de seus habitantes.

Um dos "incovenientes" da topografia carioca era o Morro de Santo Antônio. A idéia do desmonte do morro e o conseqüente aterro na Baía de Guanabara não era nova. O Morro de Santo Antônio estava localizado no centro da cidade, próximo ao mar. Seu desmonte já vinha sendo discutido desde os idos do século 18, em prol de um melhor saneamento, higiene e embelezamento da cidade. A idéia de um aterro às margens da baía, que estava convenientemente localizada perto do morro, era uma conseqüência lógica do desmonte. Isto traria à cidade duas valiosas áreas para expansão de uma só vez: uma localizada no centro da área urbana, outra localizada à beira-mar. Agache, em seu plano, reconsiderou a antiga idéia de aterrar a baía em frente ao bairro da Glória (Figura 1). Ele defendeu o desmonte usando os mesmos argumentos de 100 anos antes: questōes estéticas e higiênicas. Além disso, o arrasamento do Morro de Santo Antônio também abriria espaço para uma melhor circulação de tráfego e a criação do centro monumental da cidade (Agache, 1930). Uma das mais interessantes e reveladoras propostas de desenho urbano do Plano Agache foi o centro monumental projetado para a área a ser aterrada, centro este que ele denominou a "Entrada do Brasil" (Agache, 1930, p.161).



Figura 1: Área de aterro proposta por Agache (1930/ na Baía de Guanabara (VII e I) depos do desmonte do Morro de Santo Antônio (V). O mapa também mostra o local onde era o Morro do Castelo (III) e o aterro resultante do seu desmonte (III) Fonte: Fornecida pela autora 
A Entrada do Brasil seria uma praça monumental de $350 \mathrm{~m} \times 350 \mathrm{~m}$, tendo a forma de um semicírculo, aberta para a baía e rodeada por palácios e edifícios governamentais (Figuras 2 e 3). Esse complexo urbanístico e arquitetônico foi projetado para ser o posto de comando, o centro governamental federal e a entrada monumental da cidade (Agache, 1930). Seria uma passagem, uma entrada simbólica (Evenson, 1973), não apenas para o Rio, mas para todo o país, pois o Rio de Janeiro ainda era a capital do Brasil naquela época.

O projeto traz um espaço organizado em linhas geométricas rígidas e uma arquitetura monumental que não possui escala humana. Um Palácio de Belas Artes e um Palácio de Comércio e Indústria foram localizados em cada lado da praça, enquanto o Senado, a Câmara dos Deputados e um auditório foram localizados de frente para o mar. Marcando a entrada da praça, duas enormes colunas reforçam o caráter solene e autoritário da área. Além disso, uma linha reta substituiria a forma curvilínea daquela parte da Baía de Guanabara.



Figura 2: A Entrada do Brasil, praça proposta por Agache (1930)

Fonte: Fornecida pela autora

São Paulo n. 13 p. 147 - 157 dez. 2000 


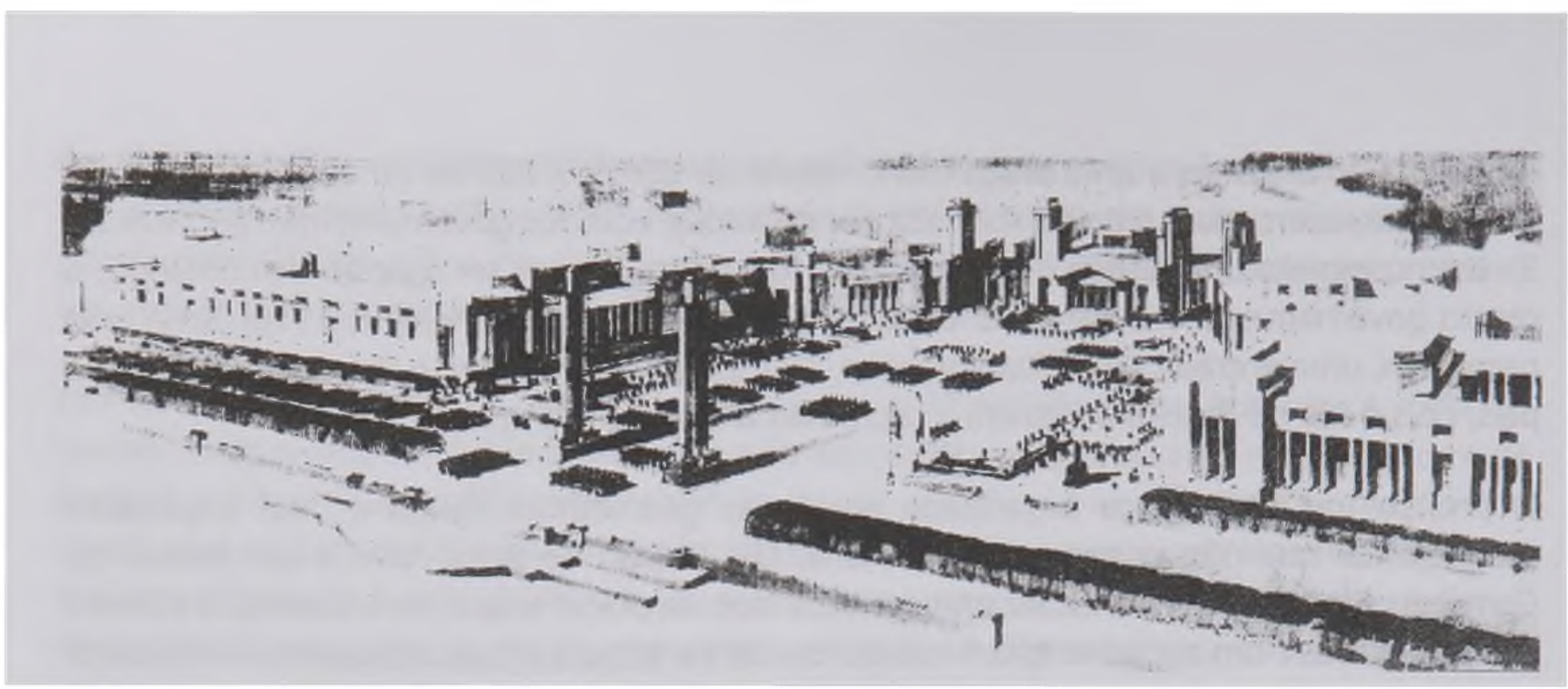

Figura 3: Perspectiva da Entrada do Brasil (Agache 1930)

Fonte: Fornecida pela autora

Na verdade essa praça cívica, descrita por Evenson (1973) como "megalomaníaca", traz em si um conteúdo ideológico que vai além de sua aparência física. Em sua análise do Plano Agache, Underwood (1991) demonstra como o plano revela claramente as escolas francesas de sociologia de 1890 a 1915 e, mais especificamente, as idéias de controle social de Durkheim:

\begin{abstract}
"A alma social do Plano Agache estava em harmonia com a subordinação dos interesses individuais ao interesse geral de Durkheim. A sólida arquitetura (...) de Agache seria uma "moldura" sociológica na qual cada indivíduo moveria na direção da formação do complexo. É esta ideologia Durkeniana de solidariedade social que vemos tão claramente na Entrada do Brasil." (Underwood, 1991. p.150)
\end{abstract}

A Entrada do Brasil, dentre todas as demais propostas de desenho urbano, é a que melhor sintetiza a ideologia que está na base do Plano Agache. As intençōes e métodos urbanísticos de Agache baseavam-se nas ciências sociais francesas e na teoria de design da Escola de Belas Artes. A transposição de idéias sociais em forma urbana, e a implícita conjugação de "boa" forma urbana em "bom" comportamento social estavam na base do urbanismo de Agache.

Estas idéias estão bem ilustradas não apenas no desenho, mas também nos usos que Agache propôs para a praça (Agache, 1930, p.161). Além de ser o centro governamental e o posto de comando da cidade e do país, a praça daria às autoridades brasileiras um espaço cerimonial, onde poderiam receber as autoridades que chegassem por mar com a devida pompa e circunstância. A Entrada do Brasil também seria um lugar para exposiçōes, em que a cidade poderia exibir suas conquistas culturais e comerciais. E, finalmente, a praça seria um lugar para paradas militares, um "espetáculo de ordem e disciplina" (Underwood, 1991, p.152), onde o povo teria uma participação limitada a de espectador passivo. Por uma boa forma urbana o carioca iria aos poucos se civilizando, por meio de um espaço urbano que sugeria disciplina, ordem e moral. 
Com o objetivo de melhorar a imagem da cidade do Rio de Janeiro, Agache justificou a importância da criação da Entrada do Brasil no aterro como:

"... um conjunto que dará à obra do homem a nota grandiosa que ainda falta à cidade. O Rio de Janeiro oferecerá, assim, à admiração do visitante chegado por mar, uma entrada monumental correspondente a importância e aos destinos da capital". (Agache 1930, p.161)

Essa passagem nos revela que, na visão de Agache, o Rio de Janeiro não tinha nenhum atributo urbano existente que fosse "magnífico" ou "monumental" Era necessário criá-los artificialmente por meios arquitetônicos e urbanísticos. No entanto, a vista espetacular da cadeia de montanhas cobertas por florestas, que se apresenta aos visitantes a chegarem por mar ao Rio de navio é, por si só, uma "entrada monumental" completamente desconsiderada por Agache. Os visitantes, em sua maioria, mostraram-se profundamente emocionados com a dramática paisagem natural, que é vislumbrada ao se chegar ao Rio de navio. Apenas dois exemplos serão suficientes para nos trazer o sabor destas experiências:

\begin{abstract}
"A primeira vez que alguém entra na Baía de Guanabara do Rio de Janeiro marca uma época na sua vida (... / a colossal avenida de montanhas e ilhas cobertas de palmeiras que, como pilastras de granito (...), formam a digna colunata para a mais bela baia do mundo." (D. P. Kidder e J. C. Fletcher, 1851, citados em Bandeira, M. e Andrade, C. D. de, 1965, p. 20)
\end{abstract}

"Desenrolou-se sob os nossos olhos uma vista maravilhosa da baia, das ilhas verdes, flutuantes, do porto com os mastros e bandeiras sem número, e da cidade estendida ao pé da mais garbosa montanha..." (J. B. Von Spix e C. F P. Von Martius, 1817, citados em Bandeira, M. e Andrade, C. D. de, 1965, p. 201

Entretanto, elementos da paisagem natural tais como montanhas, cachoeiras e florestas nāo eram valorizados no urbanismo da Escola Francesa de Belas Artes, cujas idéias Agache se empenhava em disseminar. Em outras palavras, eles não faziam parte do padrāo cultural de desenho urbano que Agache estava tentanto trazer para a cidade do Rio de Janeiro. Mais do que isto, montanhas e florestas simbolizavam um espaço urbano que estava ainda selvagem e primitivo, à espera de ser "civilizado" Era necessário criar uma "entrada monumental" artificial para a cidade já que, sob o ponto de vista de Agache, a "entrada monumental" natural não existia.

A finalização do Plano Agache coincidiu com a Revolução de 1930, que levaria ao regime autoritário de Getúlio Vargas ao Estado Novo em 1937 Com essa mudança de governo no país, o plano representava uma conquista da administraçāo anterior e portanto não poderia ser implementado (Reis, 1965, Rezende, 1982). Dessa forma o Plano Agache foi oficialmente suspenso em 1984 (Mindlin, 1956), apenas para reaparecer posteriormente com o estabelecimento da Comissão do Plano da Cidade em 1937. 


\section{Consideraçōes finais}

Esta breve reflexão sobre a Entrada do Brasil proposta por Agache nos mostra que a paisagem pode ser estudada enquanto uma construção cultural, que se dá num processo contínuo de transformação e reinterpretação no tempo e no espaço. Nessa dinâmica, valores e significados são atribuídos à paisagem e se materializam em propostas de uso, forma e caráter.

No local onde Agache previu a Entrada do Brasil temos hoje a Marina da Glória, não como um elemento autônomo, mas sim como um dos equipamentos do Parque do Flamengo (Foto 4). O perímetro curvilíneo da Marina junto ao mar, hoje tão característico da paisagem urbana carioca, foi projeto do arquiteto Affonso Eduardo Reidy, ainda no final dos anos 40 , muito antes da concepção do parque ${ }^{2}$ Não cabe aqui uma discussão sobre o longo processo de desenho dessa área da cidade que resultou no Parque do Flamengo ${ }^{3}$ mas é importante ressaltar que o desenho de Reidy para esse local, ao contrário do desenho de Agache, incorpora elementos da

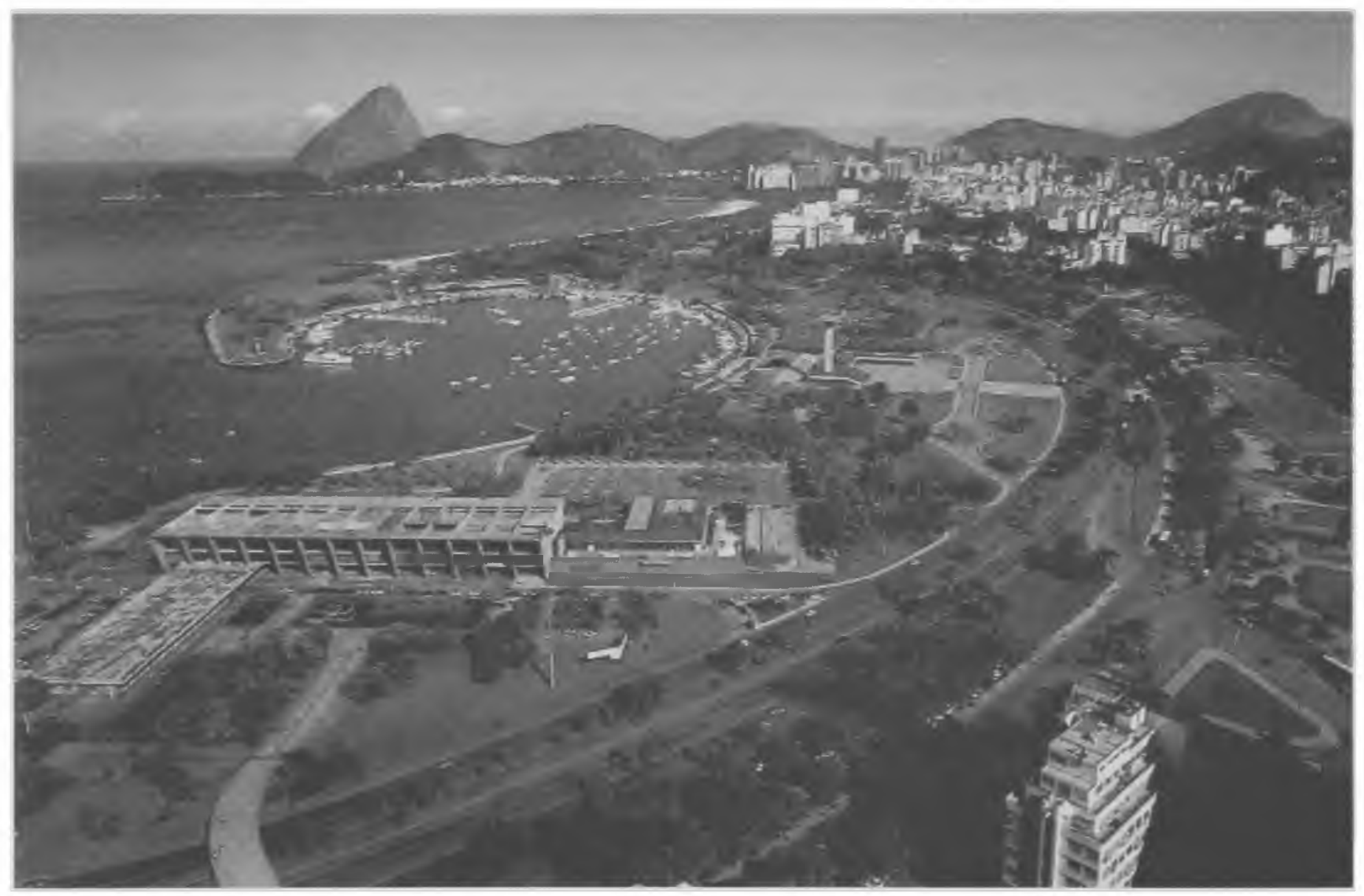

Foto 4: A Marina da Glória no Parque do Flamengo, local onde teria sido implantada a Entrada do Brasil Fonte: Fornecida pela autora

(2) Reidy foi um dos mais importantes arquitetos brasileiros que, a partir dos anos 30, procuraram trazer uma interpretação do movimento moderno internacional que fosse culturalmente específica. No início de sua carreira, fez parte da equipe de arquitetos que trabalhou no Plano Agache. Para um estudo detalhado de sua obra ver BONDUKI, N. Affonso Eduardo Reidy. São Paulo: Instituto Lina Bo e P. M. Bardi, 1999.

(3) Sobre este tema, ver Costa, 1993.

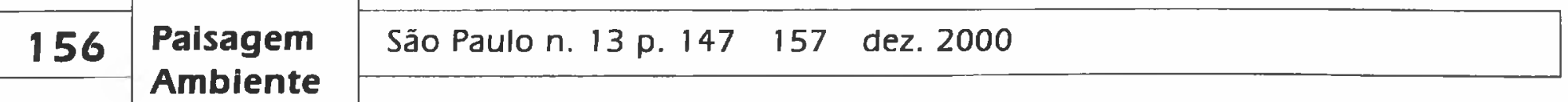


paisagem natural, sem ignorar o aspecto simbólico e monumental intrínseco ao sítio paisagístico. Este gesto projetual, por sua vez, também reflete um sistema de valores - agora vinculado ao movimento moderno internacional, porém sem perder sua vinculação com o sistema de valores culturais local.

Tuan nos lembra que a "paisagem é uma ordenação da realidade por diferentes ângulos" (1979, p. 90). Estudar os valores e significados culturais e simbólicos de nossas paisagens urbanas é, portanto, compreender que elas materializam nossa visão de mundo. A Entrada do Brasil proposta por Agache nos revela um desses diferentes ângulos de ordenação da realidade, exemplificando um dos muitos olhares estrangeiros que já pousaram sobre a cidade do Rio de Janeiro.

\section{Bibliografia}

ABREU, Maurício de A. Evoluçāo urbana do Rio de Janeiro. Rio de Janeiro: IPLAN-RIO, Jorge Zahar Editor, 1987

AGACHE, A. H. D. Cidade do Rio de Janeiro, remodelação, extensão e embelezamento. Paris: Foyer Brésilien, 1930.

BANDEIRA, M., ANDRADE, C. D. de (eds). Rio de Janeiro em prosa e verso. Rio de Janeiro: José Olympio Editora, 1965.

BRUANT, C. Donat Alfred Agache: Urbanismo, uma sociologia aplicada. In RIBEIRO, L. C. de O., PECHMAN, R. M. (org.) Cidade, povo e nação: Gênese do urbanismo moderno. Rio de Janeiro: Civização Brasileira, 1996, p. 167-201.

EVENSON, N. Two brazilian capitals: Architecture and urbanism in Rio de Janeiro and Brasilia. Londres: Yale University Press, 1973.

MINDLIN, H. M. Modern architecture in Brazil. Londres: The Architectural Press, 1956.

REIS, J. de O. As administraçōes municipais e o desenvolvimento urbano. In: SILVA, F. N. (ed.) Rio de Janeiro em seus 400 anos: Formação e desenvolvimento da cidade. Rio de Janeiro: Record, 1965, p.125-172.

RESENDE, V. Evolução da produção urbanística da cidade do Rio de Janeiro. In: LEME, M. C. da S. (coord.) Urbanismo no Brasil: 1895-1965. Sāo Paulo: FUPAN e Studio Nobel, 1999, p. 39-70.

Planejamento urbano e ideologia: Quatro planos para a cidade do Rio de Janeiro. Rio de Janeiro: Civilizaçāo Brasileira, 1982.

SILVA, L. A trajetória de Alfred Donat Agache no Brasil. In: RIBEIRO, L. C. de O., PECHMAN, R. M. (org.) Cidade, povo e naçāo: Gênese do urbanismo moderno. Rio de Janeiro: Civização Brasileira, 1996, p. 397-410.

TUAN, Y. F. Though and landscape. In: MEINIG, D. W. (ed.) The interpretation of ordinary landscapes. Oxford: Oxford University Press, 1979, p. 89-102.

UNDERWOOD, D. K. Alfred Agache, french sociology and modern urbanism in France and Brazil. Journal of the Society of Architectural Historians, 50, 2, p.130-166, 1991.

\section{Agradecimentos}

Agradecemos a Jacques Sillos de Freitas, Rachel Tardin e Maria Fernanda Lemos pelas críticas construtivas a este artigo. Esta pesquisa foi financiada pelo CNPq e UFRJ.

\begin{tabular}{|l|ll|l|l|l|l|l|l|l|l|l}
\hline São Paulo n. 13 p. $147 \quad 157$ dez. 2000 & $\begin{array}{l}\text { Paisagem } \\
\text { Ambiente } \\
\text { Ensaios } \\
13\end{array}$ \\
\hline
\end{tabular}

